\title{
Necesidad de un gobierno abierto en México
}

\section{Need for an open government in Mexico}

\author{
MADRIGAL-GUERRERO, Susana \\ Universidad Michoacana de San Nicolás de Hidalgo, Facultad de Derecho y Ciencias Sociales. Calle de Santiago Tapia \\ 403, Centro, 58000 Morelia, Mich.
}

ID $1^{\text {er }}$ Autor: Susana, Madrigal-Guerrero / ORC ID: 0000-0001-6292-3343, Researcher ID Thomson: T-8821-2018

DOI: $10.35429 /$ JLA.2019.7.3.24.40

Recibido 10 de Enero, 2019; Aceptado 28 de Marzo, 2019

\begin{abstract}
Resumen
El presente trabajo consiste en un análisis acerca de las condiciones que son necesarias para un gobierno abierto, mismas que son fundamentales para que nuestro sistema funcione como tal y se lleve a cabo como ese medio de vida que favorecerá para el desarrollo de nuestra nación. Gobierno abierto y democracia son dos caras de la misma moneda ya que las medidas para implementarlo constituyen una nueva forma de aproximarse a los ciudadanos, una revolución en la forma de utilizar la información de las administraciones públicas o, incluso, una plataforma en la que los ciudadanos se convierten en los verdaderos protagonistas de la democracia. Este trabajo tiene por objetivo general, demostrar que México necesita evolucionar hacia un gobierno abierto. Lo anterior se realizará mediante investigación documental y comparación internacional. Considero que este trabajo contribuirá al entendimiento de lo que es un gobierno abierto y de la importancia en nuestro país de transitar de una vez a este tipo de gobierno.
\end{abstract}

Gobierno abierto, Democracia, Evolución

\begin{abstract}
The present work consists of an analysis about the conditions that are necessary for an open government, which are fundamental for our system to function as such and be carried out as that livelihood that will favor the development of our nation. Open government and democracy are two sides of the same coin since the measures to implement it constitute a new way of approaching citizens, a revolution in the way of using information from public administrations or even a platform in which citizens become the true protagonists of democracy. The objective of this work is to demonstrate that Mexico needs to evolve towards an open government. The foregoing will be done through documentary research and international comparison. I believe that this work will contribute to the understanding of what an open government is and the importance in our country of transiting at once to this type of government.
\end{abstract}

Open government, Democracy, Evolution

Citación: MADRIGAL-GUERRERO, Susana. Necesidad de un gobierno abierto en México. Revista de Aplicaciones del Derecho. 2019. 3-7: 24-40.

\footnotetext{
*Correspondencia al Autor (Correo Electrónico: oliversusanito@ hotmail.com)

$\dagger$ Investigador contribuyendo como primer autor.
} 


\section{Introducción}

Hoy en día el término gobierno abierto está teniendo un gran impacto, especialmente en los gobiernos democráticos $y$ en sus administraciones, son vox populi (la voz del pueblo) los principios que lo sustentan: transparencia, participación y colaboración; el mecanismo que lo desarrolla; las Tecnologías de la Información y la Comunicación (TIC), así como las diferentes iniciativas implementadas por los gobiernos como portales de transparencia, open data o fomento de la participación ciudadana, entre otras. La crisis de legitimidad de los gobiernos y las administraciones públicas ha supuesto un gran impulso para implementar las ideas de gobierno abierto en la actualidad.

Gobierno abierto y democracia son dos caras de la misma moneda ya que las medidas para implementarlo constituyen una nueva forma de aproximarse a los ciudadanos, una revolución en la forma de utilizar la información de las administraciones públicas o, incluso, una plataforma en la que los ciudadanos se convierten en los verdaderos protagonistas de la democracia. Por ello, se iniciará con una revisión de sus orígenes para comprender que es un concepto intrínseco de la propia democracia, que se ha ido desarrollando con el paso del tiempo unido a la evolución de las diferentes teorías de la administración pública. De igual manera se abordará la democracia, haciendo referencia en la democracia participativa, misma que se basa en gran medida en la participación ciudadana como un requisito fundamental de gobierno abierto, ya que es ésta la que favorece que se den todos los principios sobre los que aquél se sustenta.

\section{Antecedentes}

Hacia los años ochenta del siglo XX, el ascenso de los gobiernos de Margaret Thatcher en Inglaterra y de Ronald Reagan en Estados Unidos trajo consigo el impulso y la aplicación de políticas económicas de corte neoliberal en sus países, las cuales se extendieron a los demás países desarrollados y otras regiones como América Latina. Estas políticas se orientaron a desmantelar al llamado Estado de Bienestar y a aplicar diferentes medidas de liberalización económica, privatización, desregulación y apertura.
Para los gobiernos, estas políticas implicaron llevar a cabo un proceso para su redimensionamiento, que significó disminuir su tamaño administrativo, reducir su injerencia en la economía y actuar dentro de un marco de reglas de competencia. Este proceso redefinió la actividad económica del gobierno así como la esfera pública, privada y social.

En esta misma etapa, cobraron auge y se desarrollaron una serie de ideas, principios y técnicas basadas en la gerencia privada; pero aplicadas en la Administración Pública, corriente que en su conjunto se denominó la Nueva Gestión Pública, la cual generó una tendencia importante en el ámbito académico y se comenzó a aplicar de forma significativa en los países desarrollados terminando por exportarse a otras regiones del mundo. La Nueva Gestión Pública, se aplicó en macro y micro procesos de la Administración Pública, utilizando diferentes técnicas gerenciales orientadas a rediseñar estructuras $\mathrm{y}$ procedimientos administrativos, generar nuevas dinámicas de trabajo y optimizar el uso de los recursos humanos, materiales y financieros. Todo esto con el fin de elevar los niveles de desempeño laboral, de eficiencia y eficacia administrativas.

Como puede advertirse, en el proceso de redimensionamiento de los gobiernos, los principios y técnicas de la Nueva Gestión Pública encontraron un excelente campo para su aplicación. Sin embargo, la evolución del contexto económico, político y social de los últimos cuarenta y cinco años, ha complejizado significativamente el ámbito de actuación de los gobiernos y de sus administraciones públicas, ya que han generado nuevas demandas y se han acrecentado otras que se venían arrastrando, generando problemas de ingobernabilidad.

En esta etapa la economía se globalizó, la interacción de las empresas, las instituciones financieras, los mercados de las naciones, el conocimiento y las innovaciones tecnológicas para elevar la productividad, entre otros factores, rebasaron las fronteras políticas de los países avanzando hacia esquemas de integración y libre flujo de mercancías, capitales, tecnologías, servicios y personas. 
En el ámbito político, la caída del muro de Berlín significó el desvanecimiento del mundo bipolar y el predominio del modelo de democracia liberal como forma de gobierno a seguir en Occidente (incluyendo a América Latina), en muchos países de Asia, Oceanía y algunos países de África. Esto ha impulsado en mayor o menor medida, la adopción y/o mayor desarrollo de diferentes instituciones y procesos democráticos como la celebración de elecciones, el sistema de contrapesos entre los poderes públicos y el establecimiento y defensa de diferentes derechos. Respecto a estos derechos, es importante mencionar que después de los de carácter civil y político como el derecho a votar, a la propiedad privada o a la libertad de expresión, durante el siglo XX se desarrollaron los de segunda generación de tipo social como el derecho a la educación, la salud, la información, cuyo ejercicio pleno ha estado en constante tensión con intereses a los que se contraponen diferentes agentes del mercado, grupos políticos, actores de los gobiernos e incluso organizaciones de la sociedad civil con visiones particulares de un tema o política.

En particular es necesario señalar que a diferencia de la etapa de la posguerra, cuando alcanzó su mayor desarrollo el Estado de Bienestar y se contuvo en cierta medida la concentración de la riqueza, en los últimos cuarenta años tanto en los países desarrollados como en el resto del mundo, se ha acrecentado dicha concentración de forma clara, provocando fuertes desigualdades y tensiones sociales $\mathrm{y}$ políticas.

Así, este escenario económico, político y social representa grandes y complejas tareas para los gobiernos, que si bien han desarrollado mejores niveles de respuesta, no han estado exentos de actuaciones erráticas que han desvelado casos de corrupción de sus gobernantes o falta de eficiencia y eficacia en el desempeño gubernamental. El deficiente desarrollo de las instituciones democráticas, ha llevado a malos desempeños de sus gobernantes; bajos niveles de profesionalización de la Administración Pública; problemas para el diseño, implementación, evaluación y continuidad de las políticas públicas; ineficiencias y corrupción en el ejercicio y control del gasto público; así como falta de eficiencia en procesos de gestión, atención y solución de las demandas de la sociedad, entre otros.
Lo anterior ha erosionado la credibilidad y confianza en los gobiernos provocando el distanciamiento de la sociedad. La credibilidad y confianza son aspectos subjetivos que requieren de enormes esfuerzos para construirlos socialmente y demandan acciones constantes que las reafirmen, ya que bastan unas pocas señales desfavorables $o$ incertidumbres para que lo construido se venga abajo. Las viejas demandas ciudadanas de democratización de los procesos políticos, el cumplimiento de los derechos ciudadanos, mejoramiento de la calidad de vida, así como mayores y mejores oportunidades de desarrollo económico, tienen un saldo desfavorable.

Aunado a lo anterior, ha sido constante el descubrimiento de casos de corrupción en las contiendas por acceder a los puestos de representación popular, en diferentes acciones de los gobiernos, en la forma de hacer negocios y en la competencia por ganar sectores del mercado. Esta situación ha generado en la ciudadanía una percepción generalizada de que la corrupción es un modus vivendi en nuestra sociedad.

Uno de los esfuerzos realizados para hacer frente a la negativa percepción de los gobiernos, ha sido la formulación y aplicación de leyes de transparencia y acceso a la información, a fin de obligar a las administraciones a exponer al escrutinio público sus procesos de elaboración e implementación de políticas públicas; el ejercicio del presupuesto público; así como sus procedimientos administrativos y el uso de los diferentes tipos de recursos destinados a realizar sus funciones.

A manera de antecedente, cabe señalar el caso de Suecia que ya en el año de 1766 adoptó una ley para permitir a los ciudadanos acceder a la información de sus organismos públicos. Por su parte, en 1966, Estados Unidos formuló su propia ley en esta materia.

Posteriormente, la mayoría de los países de Europa aprobaron leyes de transparencia y acceso a la información pública, a los que se sumaron Japón, Corea del Sur, Canadá, Australia y Nueva Zelanda. 
En América Latina, entre el año 2002 y 2012, aprobaron sus respectivas leyes en esta materia: Brasil, Chile, Colombia, Ecuador, El Salvador, Guatemala, Honduras, México, Nicaragua, Panamá, Perú, República Dominicana y Uruguay. En 2014 Oszlak ya señalaba que alrededor de 100 países ya contaban con legislación sobre trasparencia y acceso a información pública (Oszlak, 2014:14). Hace algunos años el concepto Gobierno Abierto era un ideal donde sólo algunos países se encontraban en vías de aplicar políticas consecuentes con aquella idea.

Afortunadamente, gracias al arduo y coordinado trabajo de los países del mundo, actualmente el concepto ha traspasado la barrera teórica y se ha llenado de contenido, materializándose en políticas concretas y casos de éxito. Incluso, con los años el concepto ha evolucionado y hoy día podemos hablar de Estado Abierto haciendo referencia a una extensión de los principios del Gobierno Abierto a todos los niveles y poderes del Estado. A pesar de los amplios avances que se han dado en la materia, quedan aún desafíos por abordar. Uno de ellos es de carácter nodal: el Gobierno Abierto no es una variable más a tener en cuenta dentro del espectro de políticas de un Estado, el Gobierno Abierto es una nueva forma de gestión pública. Se presenta ante nosotros como un nuevo marco que debe impregnar todos los aspectos públicos.

El desafío consiste entonces en tomar al Gobierno Abierto como la matriz que articula todo el proceso de gestión pública. La planificación, el presupuesto, la ejecución, el seguimiento y evaluación de políticas públicas deben estar basados en este nuevo paradigma.

Es así que, el paradigma de gobierno abierto constituye un eje fundamental para cumplir con los Objetivos de la Agenda 2030 para el Desarrollo Sostenible, cuyo objetivo consiste en configurar un nuevo marco de gobernanza pública y una renovada arquitectura estatal que permitan promover sociedades pacíficas e inclusivas para el desarrollo sostenible, facilitar el acceso a la justicia para todos y construir a todos los niveles instituciones eficaces, responsables e inclusivas que rindan cuentas.

En base a todo esto, Alicia Bárcena, Secretaria Ejecutiva de CEPAL argumenta:
"El quehacer de lo público no se trata sólo de lo que haga o deje de hacer el gobierno. Se trata de fortalecer lo colectivo, lo de todos, con plena conciencia y con derechos y responsabilidades. Son bienvenidas las acciones de los gobiernos en la dirección de la transparencia, la participación y la justicia, y es necesario que participen las otras instancias del Estado, es decir, además del poder ejecutivo, el legislativo y el judicial, y también los niveles subnacionales de gobierno." (Bárcena, 2015).

\section{Democracia Participativa}

Antes de empezar a indagar sobre el concepto principal del presente trabajo, debemos hacer referencia al sistema político en el cual se enmarca, es decir, la democracia. En el mundo contemporáneo de hoy en día existe una amplia diversidad de visiones y usos posibles para la definición del concepto de democracia, se usa como sinónimo de libertad, igualdad, gobierno de mayoría, justicia social, y fraternidad; lo cierto es que la democracia no solamente constituye un régimen político, que implica no solo una forma de gobierno, una estructura económica y social, sino también valores, actitudes y conductas democráticas, que conforman un sistema de vida en el que todos los ciudadanos ya sea gobernantes y gobernados realizamos prácticas democráticas que contribuyen en los aspectos de nuestra vida, mismos que nos llevan a buscar un verdadero Estado de Derecho. Aunado a ello es importante señalar que la democracia es un sistema político que impera en la mayoría de los países del mundo y México es uno de ellos.

"El termino democracia deriva de los vocablos griegos demos, que significa pueblo y kratos, gobierno o poder" (Ticas, 2011: 114). A partir de su origen etimológico la palabra democracia hace referencia al gobierno o poder del pueblo, actualmente se llama así al sistema político, en el que los ciudadanos participan por medio del voto en la elección de sus representantes, entre ellos, presidente, senadores y diputados, tal como se hace en México. Desde que nacemos pertenecemos a diversos grupos o asociaciones, iniciándose en la familia hasta llegar a la formación de los estados, en los que debemos tomar decisiones que afectan a la colectividad de la asociación como, por ejemplo, los objetivos que se van a perseguir, las reglas que se deben cumplir o la distribución de las responsabilidades y los beneficios de sus miembros. 
La democracia forma parte de esta esfera, en la que dichas decisiones deben ser tomadas por todos sus miembros, gozando cada uno de ellos del mismo derecho en la toma de decisiones. Con esta explicación quedan claras dos cosas: en primer lugar, que la democracia no pertenece únicamente a la esfera del Estado, ya que los principios democráticos son aplicables en cualquier asociación, aunque, en el ámbito estatal, tienen una gran relevancia debido a que corresponde a que regula los asuntos de la sociedad en su conjunto; en segundo lugar, que la democracia es una cuestión de grado, es decir, de la aplicación en mayor o en menor grado de los principios de control popular y de igualdad de derechos y participación sobre la toma colectiva de decisiones. Por consiguiente, en los Estados democráticos será el gobierno el encargado de garantizar los derechos civiles y políticos y de llevar a cabo elecciones pluralistas en las que todos los adultos tienen igual derecho de voto y de presentar su candidatura en ellas.

La democracia en México siempre será un tema de análisis y reflexión, ya que su sola comprensión e interpretación, motiva una variedad de opiniones, dígase bien, para estar a favor o en contra. En la actualidad, existen una diversidad de visiones acerca de la democracia, y en casi todas, la palabra democracia se usa como sinónimo de libertad, igualdad, justicia social, fraternidad, gobierno de mayoría, etc., lo que si podemos decir es que, la democracia constituye un régimen político, que implica no solo una forma de gobierno, sino también conductas democráticas, actitudes y valores, pero sobre todo un verdadero Estado de Derecho. Es importante recalcar que la democracia es un sistema político que rige en la mayoría de los países del mundo. Para el estudio de la democracia, es necesario entrar en la siguiente definición, misma que la señala como "un gobierno directo del pueblo que se basa en defender un sistema en que todos los ciudadanos, libres e iguales, pudieran llegar a manifestar su evolución, para lograr obtener un acuerdo común, un contrato social" (Rousseau, 1993: 65). De lo anterior podemos decir que, la democracia es aquella que no se propone limitar el poder sino distribuirlo de forma igual entre todos los miembros de la sociedad. Por este camino llegará a una fórmula sumamente relevante para nuestro análisis: una especie de democracia absoluta en la que el poder se distribuye sin limitaciones.
Hay que señalar que una democracia ideal, es aquella que está enmarcada en un pequeño territorio, ya que así es más fácil concurrir a las asambleas o reuniones, y por ende más fácil conocer a los demás conciudadanos en dichas reuniones; también, tiene que haber una relativa igualdad material entre los ciudadanos "sin lo cual la igualdad no podría subsistir por largo tiempo en los derechos y en la autoridad; en fin, poco o ningún lujo, porque éste corrompe a la vez al rico y al pobre: a uno por su posesión, y al otro por la envidia" (Rousseau, 1993: 67).

Asimismo, estos cinco criterios deben ser satisfechos en el proceso de gobierno de esta asociación:

- Participación efectiva. Todos los miembros deben tener oportunidades iguales $\mathrm{y}$ efectivas para hacer que sus puntos de vista sobre cómo tenga que ser la política sean conocidos por los otros miembros.

- Igualdad de voto. Todo miembro debe tener una igual y efectiva oportunidad de votar, y todos los votos deben contar como iguales.

- Comprensión ilustrada. Todo miembro debe tener oportunidades iguales y efectivas para instruirse sobre las políticas alternativas relevantes y sus consecuencias posibles.

- Así pues, dentro de los límites y espacios razonables de tempo, los miembros deben de tener oportunidades iguales y efectivas para instruirse acerca de las posibles políticas relevantes y analizar sus posibles consecuencias.

- Control de la agenda. Los miembros deben tener la oportunidad exclusiva de decidir cómo y, si así lo eligen, qué asuntos deben ser incorporados a la agenda. Así el proceso democrático exigido por los tres criterios anteriores nunca se cierra. Las políticas de los asociados están siempre abiertas a los cambios que puedan sobrevivir o que los propios miembros quieran introducir.

- Inclusión de los adultos. Todos o, al menos, la mayoría de los adultos que son residentes permanentes, deben tener los plenos derechos de ciudadanía que están implícitos en los cuatro criterios anteriores (DAHL, 2006: 136-137).

MADRIGAL-GUERRERO, Susana. Necesidad de un gobierno abierto en México. Revista de Aplicaciones del Derecho. 2019 
La razón de estos criterios es sencilla, cada uno de ellos es necesario si los miembros de la comunidad, independientemente de cuál sea su número, políticamente son iguales a la hora de tomar decisiones. Por lo tanto, la exclusión de alguno de estos criterios invalida el proceso democrático, y sus miembros dejarían de ser políticamente iguales. En este contexto, si algún o algunos de los miembros se otorgan mayores oportunidades de expresar sus puntos de vista, sus opiniones o propuestas políticas tienen mayores posibilidades de imponerse o de prevalecer.

En el caso extremo reducir oportunidades de participar y expresar sus ideas, queda cubierto por el derecho a la participación efectiva. Los dos primeros criterios parecen evidentes en sí; serán cuestionados en el sentido de que podría ser necesario o apropiado un criterio de la comprensión ilustrada. Si los miembros están políticamente igualados, resulta improcedente imponer un criterio de calificación ilustrada, por lo que resulta completamente contradictorio.

La Constitución Política de los Estados Unidos Mexicanos lo contempla de la siguiente manera en su artículo $40^{\circ}$ señalando que, "es voluntad del pueblo mexicano constituirse en una República representativa, democrática, laica, federal, compuesta de Estados libres y soberanos en todo lo concerniente a su régimen interior..." también hay que señalar que nuestra misma constitución establece en su artículo $3^{\circ}$ “....considerando a la democracia no solamente como una estructura jurídica y un régimen político, sino como un sistema de vida fundado en el constante mejoramiento económico, social y cultural del pueblo..." dicho artículo también establece la concepción integral de la democracia como un sistema que busca acercarse cada vez más a la realización de los valores democráticos. Por tal razón en México tenemos una democracia económica y social, y no solamente política. La fortaleza de la democracia se sitúa en la constitución, pues es en esta donde se encuentran sentadas sus bases, ya que como carta fundamental establece la organización y atribuciones del poder público, así como también reconoce y garantiza la tutela y proyección de los derechos fundamentales de las personas.
Se considera que la democracia es una forma de organización que lleva inmersos los valores de libertad, respeto, unidad y representatividad entre los miembros de una sociedad, para poder organizarse de una manera en la que todos participen y tomen decisiones encaminadas al bienestar de todos, haciéndolo en un ambiente donde exista una cultura política y conciencia ciudadana. Ahora bien, el fundamento principal de la democracia, es el reconocimiento de la dignidad de la persona humana. Considerando que las personas son libres y conscientes de su libertad y, por lo tanto, tienen la facultad de decidir y elegir conforme a su libre albedrio. La democracia es la forma de organización social y política que mejor garantiza el respeto, el ejercicio y promoción de los derechos humanos. La democracia, al igual que los seres humanos es perfectible, esto quiere decir que, va cambiando y se puede enriquecer y mejorar conforme a las necesidades sociales y culturales.

Podemos afirmar que hay cinco características que hacen visible a la democracia dentro de un Estado. La primera sería que la democracia, como hemos dicho anteriormente, se basa en el principio de igualdad, lo que se traduce en el hecho de que no solamente las opiniones de las personas tengan el mismo peso sino que, además, el Gobierno atienda los intereses de las personas por igual. Podemos decir, como segunda peculiaridad, que cuanto más participen las personas en la dirección de la política, mejor reflejadas estarán sus preocupaciones y aspiraciones en ella y, por tanto, será más apto para responder a dichas necesidades un Gobierno democrático. Como tercera, tendríamos que este sistema político depende del debate abierto, expresando todas las opiniones aunque sean diferentes y cada una con el mismo derecho de ser escuchada, junto con la persuasión y el acuerdo. La cuarta característica es que la democracia garantiza las libertades fundamentales como, por ejemplo, la libertad de palabra, expresión, sindical, tránsito, seguridad de la persona etcétera, ya que el debate abierto no podría producirse sin su existencia. Por último, la democracia permite la renovación social, ya que se prevé el reemplazo normal y pacífico de las líneas políticas en el gobierno sin que se produzca una desorganización gubernamental (Beetham y Boyle, 1996: 18-19). 
Una vez que han sido sucintamente establecidos tanto el concepto como las características de la democracia, debemos indagar sobre cómo instaurar este sistema político dentro de un Estado.

El filósofo liberal del siglo XIX, J.S. Mill (1994), sostenía que: "el gobierno democrático suponía un grado avanzado de civilización y en el caso de que esa sociedad no cumpla las condiciones necesarias para ello, no será el tipo de gobierno adecuado para ese grado primitivo de civilización" (Mill, 1994: 16-17).

Además de tener un grado avanzado de civilización, otros factores que pueden contribuir al impulso de la democracia son la educación de la población, el apoyo de las democracias extranjeras y la lucha y movilización popular extendidas en largos períodos de tiempo.

A partir de la instauración y del mantenimiento de la democracia como sistema político en funcionamiento dentro de un Estado, podemos observar cuáles son sus principales componentes. Beetham y Boyle (1996) establecen cuatro elementos principales de una democracia en funcionamiento:

- Elecciones libres y limpias: son fundamentales para que se desarrolle competencia política entre diferentes partidos políticos. También que sus gobernantes, así como todos sus funcionarios públicos, estén sometidos al control popular, es decir, sean responsables ante los ciudadanos. Además, las elecciones garantizarán la igualdad política entre los ciudadanos, tanto en el acceso de estos a los cargos públicos como en el valor de sus votos.

- Gobierno abierto y responsable: por un lado, un gobierno democrático debe ser sensible a los problemas y necesidades de los ciudadanos y estar abierto a que todos expresen su opinión públicamente. Por otro lado, un gobierno democrático debe ser responsable ante los tribunales, ya que debe velar por el cumplimiento de la ley, así como ante el parlamento y los ciudadanos, a los que deberá justificar sus políticas e iniciativas.
- Derechos civiles y políticos: la democracia garantiza las libertades fundamentales, ya que, gracias al reconocimiento de estos derechos civiles y políticos, los ciudadanos podemos organizarnos colectivamente $\mathrm{y}$ ejercer influencia en el Gobierno.

- Sociedad democrática: es necesaria la existencia de asociaciones democráticas de todo tipo, organizadas independientemente del Estado, para que así los ciudadanos puedan formar su propia opinión pública sin estar manipulados por el Gobierno y, por tanto, puedan tener capacidad de decisión propia y fomenten la existencia de ciudadanos activos y responsables de la situación de la sociedad (Beetham y Boyle, 1996: 37-38).

En el contexto de la democracia, el gobierno abierto es uno de sus elementos principales. Autores como Ramírez-Alujas (2012) señalan que tendríamos que remontarnos hasta la mitad del siglo XX para observar su aparición en las primeras agendas y debates oficiales, pues es en ese momento en el que comienzan a sucederse una serie de presiones a través de movimientos ciudadanos para mejorar el acceso a la información.

Es importante analizar la democracia como forma de gobierno, ya que es "el tipo de democracia que llevaba a un grado más alto el ideal de esa forma de gobierno era la democracia directa" (Fernández, 2013: 9), entendida como aquélla forma en la que se reunían en una asamblea soberana los individuos que gozaban de derechos políticos, sin mediación alguna de representantes, para tomar decisiones obligatorias para todos los miembros de la ciudad-Estado. Esa fue sustancialmente la manera en que se practicó el gobierno popular en el mundo antiguo. Tal convención de ciudadanos no se integraba por lo que hoy llamaríamos partidos políticos ni procedía por votación.

La democracia no se limita únicamente a una técnica para tomar decisiones, sino que desde la antigüedad se le considera como una forma de gobierno, una manera de gobernar, o de dirigir la sociedad. 
La democracia participativa contiene una diversidad de formas de participación, sin embargo, todas encerradas en un mismo ideal, los ciudadanos deben ser más activos, informados y racionales no sólo para elegir a sus representantes, sino también para participar en la toma de decisiones. Esto se da en función de una mejor educación ciudadana, desarrollo de una cultura política e incluso en debates públicos que permitan discutir las diferentes opciones.

La democracia, "tiene que ver con un sistema político que proporciona elecciones periódicas para el cambio de gobernantes, permitiendo la participación de la mayor parte de la población para influir en la toma de decisiones mediante la elección de los gobernantes para que ocupen un cargo público" (DUVERGER, 2001: 53) Por otro lado, "la democracia solo se dará en la medida en la que los ciudadanos estén más involucrados activamente en el proceso político, siendo elemento indispensable la educación de los ciudadanos, reconociendo los intereses mutuos como "factor del control social" para así generar un cambio continuo en los hábitos sociales" (DUVERGER, 2001: 53). Con ciudadanos educados se podrían hacer mejores elecciones y para obedecer las resoluciones que dictaban sus gobernantes.

Por tanto, se considera que una sociedad es democrática en la medida en la que se facilita la participación de los ciudadanos en condiciones iguales. Sin embargo, es necesario saber que las condiciones básicas que deben darse son la libertad de los individuos para elegir a sus gobernantes en elecciones periódicas, y además deben complementarse con tres dimensiones, el respeto a los derechos fundamentales, que los individuos se sientan ciudadanos y la representatividad de los dirigentes. Se considera que para que se dé una auténtica democracia debe darse una participación más amplia de la población, en donde todos los ciudadanos cuenten con el derecho y la facultad de ser activos si así lo desean. Tanto la democracia participativa como la ciudadanía descansan sobre la participación, es así que, el tener ciudadanos activos, brindará nuevas oportunidades para participar en la regulación de los sistemas de toma de decisiones en la sociedad. Por lo tanto, para alcanzar un mayor grado de democracia, es necesario robustecer los sistemas de participación ciudadana.

ISSN 2523-0263

ECORFAN® Todos los derechos reservados

\section{Gobierno Abierto}

En los años recientes el término de Gobierno Abierto ha llamado mucho la atención, tanto en el ámbito académico como en gobiernos de diferentes regiones del mundo. Las propuestas, ideas, principios y conceptos que plantea, han sido retomados por diferentes autores en el mundo a fin de reflexionar, ampliar su contenido, realizar precisiones conceptuales y formular críticas. El concepto de Gobierno Abierto ha emergido como un nuevo enfoque aglutinador de esfuerzos por mejorar las capacidades del gobierno y modernizar las administraciones públicas bajo los principios de la transparencia y apertura, la participación y la colaboración, sin embargo se hace necesario abordar conceptos más específicos acerca de este tema, "el gobierno abierto surge como un nuevo paradigma y modelo de relación entre los gobernantes, las administraciones y la sociedad: transparente, multidireccional, colaborativo y orientado a la participación de los ciudadanos tanto en el seguimiento como en la toma de decisiones públicas, a partir de cuya plataforma o espacio de acción es posible catalizar, articular y crear valor público desde y más allá de las fronteras de la burocracias estatales" (Ramírez 2011: 55).

De lo que Ramírez aborda, se deduce que un gobierno abierto ofrece una mejoría tanto a sus gobernados como a la administración pública en sí, ya que da paso a la participación, la transparencia, la pluralidad de las masas, y con ello al bienestar de la colectividad en sí. De igual manera no está por demás considerar que "gobierno abierto se trata de una nueva cultura de la comunicación, un nuevo modelo organizativo y la liberación del talento creativo dentro y fuera de los perímetros de la función pública..." (Gutiérrez, 2011: 77).

Un gobierno abierto, es un gobierno que abre sus puertas al mundo, se involucra con todos, especialmente con los ciudadanos; comparte recursos que anteriormente estaban celosamente guardados, y aprovecha el poder de la colaboración masiva, la transparencia en todas sus operaciones, y no se comporta como un departamento o jurisdicción aislada, sino como una estructura nueva, como una organización verdaderamente integrada y que trabaja en red. 
Al respecto se entiende por gobierno abierto "aquel que entabla una constante conversación con los ciudadanos con el fin de escuchar lo que ellos dicen y solicitan, que toma decisiones basadas en sus necesidades y teniendo en cuenta sus preferencias, que facilita la colaboración de los ciudadanos y funcionarios en el desarrollo de los servicios que presta, y que comunica todo lo que decide y hace de forma abierta y transparente" (Calderón y Lorenzo, 2010: 44).

Entre los diferentes autores que han abordado el tema del Gobierno Abierto, existe el consenso de que se basa en los referidos tres principios de: transparencia informativa, participación y colaboración ciudadana. Meijer, Curtin y Hillebrandt, han señalado que hay un elemento clave: la apertura de datos, ya que si no existe un acceso libre, abierto y gratuito a la información del gobierno, no existen los mecanismos que permitan la participación y acción de los ciudadanos con dicha información. Para autores como Christmas, Naurin y Meijer, sin información disponible para los ciudadanos no es posible la deliberación ni la participación. (Campos, 2012:125-126). De esta forma, una de las condiciones básicas del Gobierno Abierto es el acceso libre, abierto y gratuito a la información gubernamental (open data), así como la existencia de mecanismos para la participación y acción de los ciudadanos con esta información (open action). Ramírez Alujas y Dassen argumentan que otro aspecto fundamental del Gobierno Abierto es: "La apertura de procesos (open process) y el uso de redes sociales (también llamado Gobierno 2.0), cuyo objeto es facilitar la comunicación y la participación, aprovechar el conocimiento y la experiencia de los ciudadanos para ayudar en el diseño de políticas y la provisión de servicios públicos, y la colaboración (en red) dentro y entre las administraciones públicas y más allá." (Dassen, 2012:46).

El Gobierno Abierto, busca ir más allá de la aplicación tecnológica para obtener mayor eficiencia y efectividad en los trámites y servicios que las instituciones públicas ponen a disposición de los ciudadanos, aspectos más relacionados con el Gobierno Electrónico. Sus planteamientos novedosos radican en que busca superar el esquema del ciudadano-cliente como sujeto separado del Estado.
Concibe a la ciudadanía como uno de los pilares fundamentales del funcionamiento del sistema. Entiende que su puesta en práctica implica una transformación profunda en el modo en que el gobierno se relaciona con los ciudadanos. Campos Domínguez y Corojan, consideran que la importancia del Gobierno Abierto no radica sólo en las tecnologías, sino que implica "reinventar el gobierno", aunque sí se fundamenta en la aplicación y uso de las TIC. Asimismo, señalan que incluye la participación ciudadana a través de la comunicación en dos direcciones: desde el gobierno a los ciudadanos y desde estos al primero. Además, afirman que el Gobierno Abierto contempla la colaboración activa entre los diferentes niveles gubernamentales y administraciones, así como entre estos y los ciudadanos (Campos, 2012:128-129).

La participación y la colaboración genera tres niveles de interacción:1) de gobierno a gobierno, que se da entre los diferentes niveles de gobierno; 2) de gobierno a empresas, en el que interactúan el gobierno y las empresas; 3) de gobierno a ciudadanos y viceversa (Campos, 2012:129-130). De igual manera señalemos que una de las definiciones más recurridas es la aparecida en el libro Open Government. Gobierno Abierto coordinado por Calderón y Lorenzo en 2010 señala lo siguiente: "Gobierno abierto es aquel que entabla una constante conversación con los ciudadanos con el fin de oír lo que ellos dicen y solicitan, que toma decisiones basadas en sus necesidades y preferencias, que facilita la colaboración de los ciudadanos y funcionarios en el desarrollo de los servicios que presta y que comunica todo lo que decide y lo hace de forma abierta y transparente." (Calderón, 2010:11).

Dada la proliferación del uso del término de Gobierno Abierto, la Organización para la Cooperación y Desarrollo Económico (OCDE), propuso en 2006 una definición basada en tres dimensiones relevantes que apelaban a una Administración Pública transparente, accesible y receptiva, con capacidad de respuesta. Para 2010, esta definición evolucionó para considerar al Gobierno Abierto como plataforma para resolver cómo el gobierno puede trabajar con la sociedad y los individuos para co-crear valor público (OCDE, 2010). 
La OCDE ha sintetizado en los siguientes puntos los posibles beneficios que se derivarían de implementar estrategias de Gobierno Abierto:

1. Restablecer una mayor confianza en el gobierno. La confianza es un resultado del Gobierno Abierto que puede reforzar su desempeño en otros aspectos. Además, si los ciudadanos confían en el gobierno y en sus políticas específicas, pueden estar más dispuestos a pagar (tasas, contribuciones, impuestos) para apoyar y financiar esas políticas.

2. Garantizar mejores resultados al menor coste. El co-diseño y ejecución de políticas, programas y (provisión de) servicios con los ciudadanos, las empresas y la sociedad civil ofrece el potencial para explotar un depósito más amplio de ideas y recursos.

3. Elevar los niveles de cumplimiento. Hacer que la gente sea parte del proceso les ayuda a comprender los retos de la reforma y puede ayudar a asegurar que las decisiones adoptadas sean percibidas como legítimas.

4. Asegurar la equidad de acceso a la formulación de políticas públicas, mediante la reducción del umbral para el acceso a los procesos de decisión que enfrentan las personas como barreras para la participación.

5. Fomentar la innovación y nuevas actividades económicas. El compromiso de la ciudadanía y del gobierno abierto es cada vez más reconocido como motor de la innovación y la creación de valor en el sector público y privado.

6. Mejora de la eficacia mediante el aprovechamiento de los conocimientos y los recursos de los ciudadanos, que de otra forma se enfrentan a barreras para participar. La participación ciudadana puede garantizar que las políticas sean más específicas y atiendan a sus necesidades, eliminando desgastes potenciales. (OCDE, 2010).

De acuerdo con Martínez Puón, el Gobierno Abierto representa un nuevo paradigma en la relación gobierno-ciudadanía, que ofrece la posibilidad de mejorar al primero al mismo tiempo que se fortalece a la segunda, bajo una lógica de ganar-ganar (Martínez, 2012).
Tradicionalmente, la relación del gobierno con la sociedad se daba básicamente a través de agrupaciones de ciudadanos, organizaciones civiles, organizaciones políticas, grupos de interés o de presión, la cual se trastoca al posibilitar una relación con el ciudadano como individuo mediante el uso de Internet y de las TIC. Esta situación ofrece nuevas perspectivas en la interactuación entre gobierno y ciudadanos. Asimismo, este autor señala que, inclusive aquellos que no tiene acceso a Internet serían beneficiarios de este nuevo paradigma como terceros beneficiarios de acuerdo a la siguiente argumentación: "Si se parte de que la reutilización de la información puede ser útil para algunos, seguramente en la difusión y socialización de la información hecha por los primeros usuarios habría un beneficio para muchos más, precisamente como parte de la gestión de la información transformada en muchos casos en conocimiento. En este sentido, la propia ciudadanía o los ciudadanos que exploten esta vía de comunicación con los gobiernos y administraciones públicas se pueden convertir en intermediarios para con los otros ciudadanos." (Martínez, 2012:150).

A nivel conceptual, el Gobierno Abierto plantea varios beneficios tanto para los gobiernos como para los ciudadanos, así como para mejorar la siempre problemática y compleja relación en éstos. Sin embargo, para llegar a establecer un esquema de Gobierno Abierto, Martínez Puón señala que es necesario cumplir con las condiciones siguientes:

- Contar con información sistematizada y que se pueda poner a disposición del público en formatos abiertos.

- Construir información donde no la hay, más aún si puede resultar útil.

- Tener una infraestructura sólida de tecnologías de la información y la comunicación.

- Tener un equipo sólido de profesionales que no sólo administren la información, sino que analicen en el interés de saber que puede ser útil y que no para la sociedad.

- Ser transparentes y rendir cuentas.

MADRIGAL-GUERRERO, Susana. Necesidad de un gobierno abierto en México. Revista de Aplicaciones del Derecho. 2019 
- Contar con normatividad suficiente y robusta que dé lugar a la apertura de la información, en la que se incluya, por ejemplo, la institucionalización, normativamente hablando, de un Catálogo de Información Pública reutilizable.

- Contar con un sitio de acceso único a la información y a los recursos.

- Registro pormenorizado de propuestas, criticas, mejoras a procesos, e historias de autogestión por parte del público.

- Consolidación de la administración en la red y para proyectos de Open Data. Movilidad (smartphones), tanto para la ciudadanía como para la Administración Pública, y una escucha activa (qué dicen los ciudadanos) en Internet.

- Escucha activa y transparencia, apertura de datos, establecer espacios colaborativos para aprovechar el conocimiento ciudadano.

- Redes sociales como canal de reclamo y opinión ciudadana, nueva actitud de las administraciones públicas.

- Progreso de las herramientas de gestión y monitorización.

- Nuevas estrategias de servicios públicos digitales para aprovechar la iniciativa emprendedora en la propia administración.

- Aplicaciones a partir de datos públicos, web móvil, información a través de canales como WhatsApp, ampliación de zonas Wi-Fi, evolución de Smart cities a Smart citizens, plataformas para la participación ciudadana.

- Mayor conocimiento en uso de redes sociales por parte de empleados públicos, evolución y creación de portales de datos públicos y open government, más guías de uso de redes sociales en las administraciones públicas.

- Mejor comunicación con la ciudadanía, aplicaciones móviles y canal de quejas 2.0.

- Incorporación de empleados públicos a las redes sociales y desarrollo de una cultura "de lo social" en los propios departamentos de las administraciones públicas (Martínez, 2012:147-148).
Para concluir con la conceptualización de Gobierno Abierto, en uno de los libros más recientes sobre el tema publicado en 2016, Cruz-Rubio logra desarrollar una de las definiciones más acabadas al caracterizarlo como: Una filosofía político administrativa, un nuevo paradigma o modelo de interacción política que -basado firmemente en los valores y principios de transparencia, de la democracia participativa y empoderamiento ciudadano, de la rendición de cuentas, el open data y del uso de avances tecnológicos, y en la conformación de gobiernos como plataformas que promueven la colaboración e interacción- se constituye como un modo y/o estrategia para el diseño, implementación, control y evaluación de políticas públicas y para procesos de modernización administrativa, y que ubica al ciudadano en el centro de atención y de prioridad, ofreciendo así una alternativa para la gestión de lo público. Como filosofía político administrativa, es pues diferenciable respecto de otras estrategias o filosofías políticoadministrativas diferentes (Cruz-Rubio, 2016:35).

Toda vez que se ha considerado que los tres pilares del Gobierno Abierto son la transparencia, la participación y la colaboración, en los siguientes apartados se hace una descripción más amplia de estos tres conceptos en términos de lo que han desarrollado diferentes autores como principios del Gobierno Abierto.

\section{Transparencia}

La transparencia es el requisito sine qua non de la actuación del Gobierno Abierto. Se parte de considerar que "todos los datos producidos por las administraciones públicas, son datos públicos" (Gastón, 2012:31). En este sentido, la transparencia consiste en proporcionar a la sociedad toda información que produce sobre sus procesos de gestión, formulación e implementación de sus políticas públicas, sobre la ejecución de sus programas, como medio para conocer los niveles de desempeño gubernamental, vigilar la utilización de los recursos públicos y facilitar la rendición de cuentas. La transparencia es esencial para atender las necesidades de información social, mejorar la imagen y recuperar confianza en el gobierno, además puede mejorar el diseño e implementación de las políticas públicas, combatir la corrupción y promover la participación ciudadana.

MADRIGAL-GUERRERO, Susana. Necesidad de un gobierno abierto en México. Revista de Aplicaciones del Derecho. 2019 
La información gubernamental es transparente en la medida en que sea accesible, se proporcione en formatos abiertos, usables y reutilizables y bajo licencias abiertas, en lo cual juegan un papel relevante las TIC como lo perciben claramente Quintanilla Mendoza y Gil García, para quienes: "Las tecnologías de información en el gobierno han modificado el modo como se concibe la transparencia, la cual no se refiere sólo a publicar información, sino que puede entenderse en un formato multinivel donde al divulgarse la información útil de modo sencillo y comprensible, por un lado, se fortalece la participación de los diversos actores en la integración de servicios en sitios web y por otro, se utilizan las herramientas en línea para solicitar la retroalimentación de los ciudadanos." (Quintanilla, 2013: 28). De esta manera, la transparencia está estrechamente vinculada al nuevo paradigma de datos abiertos (open data), que se propone situar todos aquellos datos públicos que no afecten a derechos fundamentales en posición de ser reutilizados por la ciudadanía, organizaciones sociales y empresas.

La transparencia gubernamental consiste en que la información sobre las actividades de los organismos públicos sea creada y esté a disposición del público, con excepciones limitadas, de manera oportuna y en formatos de datos abiertos sin límites para la reutilización. Esto incluye la divulgación de información en respuesta a las solicitudes de la ciudadanía y de manera proactiva, a iniciativa propia de las entidades públicas. Además de que la información clave acerca de los entes privados esté disponible ya sea directamente o a través de organismos públicos. Hablar de transparencia no sólo se refiere a establecer una barrera contra la corrupción y los abusos de poder, cosa que sin duda consiguen en buena medida los proyectos de apertura de datos, sino básicamente de un derecho de todo ciudadano a recibir información sobre lo que hacen los gobiernos con el dinero de sus impuestos. Según la Open Government Standards, los estándares de Transparencia son los siguientes:

1. Derecho a Saber: Que los gobiernos reconozcan el derecho fundamental de los ciudadanos a acceder a la información, con excepciones limitadas, y que faciliten información en respuesta a las solicitudes y de manera proactiva.
2. Toda la información, de todos los organismos públicos: Que el derecho de acceso a la información sea aplicado a toda la información en poder de organismos nacionales y supranacionales, incluidos todos los órganos que desempeñan funciones públicas y que operan con fondos públicos (esto incluye a los poderes legislativo y judicial, y las empresas privatizadas que ejercen funciones públicas así como las entidades privadas que posean información relacionada con o que sea necesaria para la protección de los derechos humanos).

3. El acceso es la regla - El secreto es la excepción: La información puede ser retenida sólo si su divulgación podría causar un daño demostrable a intereses legítimos de lo permitido por el derecho internacional, y sólo después de considerar el interés público en la dicha divulgación. Estos intereses deben ser protegidos de manera clara y específicamente definidos en la legislación nacional, y debe aplicarse sobre una base de caso por caso. Las mismas excepciones para mantener la información divulgada en respuesta a las solicitudes de acceso a la información y que se describe de forma proactiva, incluso bajo las políticas de datos abiertos.

4. Publicación proactiva: Que las entidades públicas deban publicar de manera proactiva información de interés público, haciendo los esfuerzos necesarios para asegurar el acceso fácil, rápido, efectivo y práctico a dicha información.

5. De carácter gratuito y libre para su reutilización: Que la información se haga pública sin cargo (el estándar internacional prevaleciente es que las solicitudes de información son gratuitas y los únicos cargos que se pueden aplicar son aquellos costes por copiar o costes asociados con la entrega de información) y sin límites en reutilización, incluyendo los impuestos por las licencias u otras restricciones; el derecho a la reutilización de la información pública está en consonancia con el acceso a la información y es parte del derecho fundamental a la libertad de expresión. 
6. Formatos Abiertos: La información almacenada electrónicamente debe ser entregada a quienes lo soliciten por vía electrónica y en un formato abierto. La información publicada proactivamente siempre debe estar disponible en formatos abiertos a todo evento.

7. Recopilación de información: que los organismos públicos y las entidades privadas que entran en el ámbito de aplicación del derecho de acceso a la información deban recopilar la información necesaria para la participación pública y la rendición de cuentas. Deben asegurarse de que esta información se compila en una manera oportuna, actualizada periódicamente, y que es clara, completa y comprensible.

8. Mecanismo/Entidad de Supervisión Independiente: Que el derecho de acceso a la información sea supervisado por un organismo independiente que revise su cumplimiento, y que pueda llevar a cabo investigaciones de oficio, recibir y decidir sobre denuncias de los ciudadanos, que esté facultado para ordenar medidas apropiadas asegurando el cumplimiento y la imposición de las sanciones correspondientes si correspondiesen (Ramírez, 2013: 66).

\section{Participación Ciudadana}

En este caso haciendo referencia a la participación ciudadana, misma que sustenta y sostiene al Gobierno Abierto. Constituye la base de muchos de los otros temas vinculados a las políticas de gobierno abierto, la ciudadanía activa suele ser un enlace vital entre la transparencia y la rendición de cuentas.

La participación ciudadana, cuando no es pura impostación, se convierte en un elemento de redistribución del poder, es decir, en un eje transversal a los tres poderes definidos por Montesquieu, quien sitúa al ciudadano como comienzo y final del proceso político, es decir, en su comienzo mediante el voto, eligiendo a sus representantes, y al final del mismo ejerciendo tareas de control de la gestión e impidiendo desviaciones del mandato. Por lo tanto, aumentar la participación implica redistribuir el poder.
En un mundo cada vez más complejo, las contribuciones de los ciudadanos son un recurso imprescindible para la formulación de políticas públicas. Una adecuada toma de decisiones requiere de los conocimientos, experiencias, opiniones y valores de los ciudadanos. La implementación de las decisiones difíciles depende, en buena medida, del consentimiento, aprobación y apoyo de los ciudadanos. Las libertades civiles son los cimientos que permiten a las personas participar sin miedo y disentir pacíficamente entre ellos y con el gobierno. Los derechos humanos básicos, entre los cuales la libertad de expresión y de prensa, la libertad religiosa, la libertad de reunión y asociación, y el derecho a un juicio justo son vitales para alimentar una cultura política en la que los ciudadanos deseen participar en el debate público y puedan hacerlo.

Es importante que la participación ciudadana se diseñe correctamente, cuente con recursos adecuados y nazca del deseo genuino de involucrar al público y de tener en cuenta sus aportaciones. Unos cauces bien diseñados de participación ciudadana pueden promover un funcionamiento democrático más eficiente, legitimar al gobierno, implementar con éxito nuevas medidas y lograr nuevos resultados sociales. Según la Open Government Standards, los estándares de Participación ciudadana son los siguientes:

1. Apertura: Promover consultas públicas ampliamente, incluso por Internet, listas de correo, anuncios públicos y medios de comunicación, animando a todos a participar y en particular, a los grupos de interés comprometidos.

2. Plazos claros y razonables: Que los procesos participativos estén estructurados de manera de asegurar el tiempo suficiente para permitir que las partes interesadas puedan aprender acerca de la consulta, revisar los materiales, preparar y garantizar la calidad de los aportes considerados.

3. Información completa, clara y comprensible: Que los materiales de apoyo disponibles para los servidores públicos involucrados en los procesos de toma de decisiones se pongan a disposición de los ciudadanos; que los principales datos y su análisis deban ser presentados en una forma que sea accesible y comprensible para el público.

MADRIGAL-GUERRERO, Susana. Necesidad de un gobierno abierto en México. Revista de Aplicaciones del Derecho. 2019 
4. Colaboración activa: Que los organismos públicos sean proactivos en sus interacciones con el público, estableciendo múltiples canales para obtener información (por ejemplo, consultas en línea, audiencias públicas, grupos focales), garantizando así que todos los interesados tengan la oportunidad de participar, y que el debate en torno a un problema pueda evolucionar $\mathrm{y}$ madurar con el tiempo.

5. Procedimientos de trabajo claros: Que las reglas sobre la forma de participar en las consultas sea clara, junto con la definición de plazos y cómo deben ser suministrados los comentarios que deberán enviarse a la autoridad pública, así como los lugares y fechas de las audiencias públicas y la manera de obtener invitaciones para asistir y participar.

6. Empoderamiento: Que los procesos participativos tengan por objeto colocar la decisión final en manos del público. Todos los comentarios recibidos deben ser cuidadosamente revisados y las perspectivas presentadas deben incorporarse en la documentación sobre la decisión final. Una justificación detallada debe ser entregada sobre el por qué y el cómo se han tenido en cuenta las opiniones del público.

7. Transparencia y rendición de cuentas: Informes sobre las respuestas recibidas, y sobre quienes participaron con comunicaciones escritas o en audiencias públicas, junto con las principales observaciones presentadas, y el razonamiento por escrito explicando cómo los comentarios recibidos se tuvieron en cuenta debiendo estar todo ello disponible en un lugar de fácil acceso para que cualquier miembro del público pueda encontrarlo y consultarlo (Gastón, 2012: 88).

La participación ciudadana ha sido desde sus orígenes un elemento indispensable para el desarrollo de las regiones, es un elemento incondicional del consenso de las actividades de gobierno, ya que sin este la legitimidad de las instituciones carece de fundamento.

\section{Colaboración}

Se trata de una dinámica de cooperación entre todos los intervinientes de la política pública, que involucra lo público y lo privado en una lógica de inteligencia colectiva, sobre una plataforma de trabajo con unidad de propósito. Se trata de evitar la duplicidad de funciones y transitar del archipiélago al continente. En definitiva, la justicia abierta permite adoptar mejores condiciones, contribuye con el proceso de rendición de cuentas, refuerza la transparencia, instala un diálogo permanente entre el Estado y la ciudadanía transformando a los ciudadanos en un vigilante de la administración de justicia. El tercer principio del Gobierno Abierto, es el de la colaboración, que trata de ir más allá de la participación, busca canalizar propuestas, esfuerzos e incluso recursos que los ciudadanos y las organizaciones de la sociedad civil estén dispuestos a aportar en el proceso de diseño, implementación y control de las políticas públicas. Un gobierno colaborativo compromete e implica a los ciudadanos y demás agentes sociales en el esfuerzo por trabajar conjuntamente para resolver los problemas públicos. De acuerdo con Calderón, la colaboración que plantea el Gobierno Abierto puede darse en las siguientes vertientes:

- Colaboración gubernamental: se trata tanto de la colaboración interna de un gobierno y los departamentos que lo forman, como la colaboración de éste con otros gobiernos.

- Colaboración con la sociedad civil: las organizaciones de la sociedad civil son uno de los interlocutores por excelencia de los gobiernos, de las que se debe buscar su colaboración y aprovechar la experiencia que han acumulado en muchos de los asuntos públicos.

- Colaboración con la empresa privada y los emprendedores: estos sectores cuentan con un gran potencial de recursos humanos, materiales, tecnológicos, financieros, información, ideas y formas de organización, con los cuales los gobiernos deben establecer lazos de colaboración para canalizar estos recursos hacia sus programas en beneficio de la sociedad en su conjunto. 
- Colaboración con los ciudadanos: se trata de rescatar aportaciones de los ciudadanos individuales que tradicionalmente sólo podían colaborar mediante organizaciones sociales o políticas, pero que actualmente lo pueden hacer a través de las TIC aportando opiniones, información, ideas o vigilancia del cumplimiento de derechos y de la actuación de los gobiernos (Concha, 2012:41-42).

La colaboración requiere de un trabajo en grupo, donde la experiencia y el conocimiento se unen para crear, producir e innovar, en lo cual juega un papel relevante la producción, difusión y reutilización de información, que se ha facilitado y potenciado con el uso de las TIC. De acuerdo con Quintanilla Mendoza y Gil García, la colaboración invita a compartir información de diferentes maneras, trascendiendo el partidismo político y brindando a las administraciones públicas nuevas maneras de satisfacer las necesidades y priorizar problemas. En este sentido afirman que: "Internet, las redes, las bases de datos y las nuevas aplicaciones pueden ser utilizadas como estrategias para responder a problemas complejos que no pueden ser resueltos fácilmente de modo independiente, convirtiéndose en una herramienta que da lugar a la concepción de una administración pública mejor preparada y por tanto más funcional" (Quintanilla, 2013:33).

\section{Conclusiones}

Dentro del presente trabajo a manera de conclusión se han hecho diversas reflexiones en torno a:

PRIMERA: El Gobierno Abierto, tiene como uno de sus principales antecedentes un contexto político-social en el que los gobiernos presentaron crecientes niveles de erosión de su credibilidad y confianza hacia finales del siglo XX y principios del actual, lo que provocó un distanciamiento de la ciudadanía. La corriente de ideas del Gobierno Abierto, puede verse como una respuesta o propuesta frente a este escenario de cuestionamientos y pérdida de legitimidad de los gobiernos.
SEGUNDA: La democracia participativa contiene una diversidad de formas de participación, sin embargo, todas encerradas en un mismo ideal, los ciudadanos deben ser más activos, informados y racionales no sólo para elegir a sus representantes, sino también para participar en la toma de decisiones.

Esto se da en función de una mejor educación ciudadana, desarrollo de una cultura política e incluso en debates públicos que permitan discutir las diferentes opciones.

Por tanto, se considera que una sociedad es democrática en la medida en la que se facilita la participación de los ciudadanos en condiciones iguales.

Tanto la democracia participativa como la ciudadanía descansan sobre la participación, es así que, el tener ciudadanos activos, brindará nuevas oportunidades para participar en la regulación de los sistemas de toma de decisiones en la sociedad.

Por lo tanto, para alcanzar un mayor grado de democracia, es necesario robustecer los sistemas de participación ciudadana.

TERCERA: Un gobierno abierto, es un gobierno que abre sus puertas al mundo, se involucra con todos, especialmente con los ciudadanos; comparte recursos que anteriormente estaban celosamente guardados, y aprovecha el poder de la colaboración masiva, la transparencia en todas sus operaciones, y no se comporta como un departamento o jurisdicción aislada, sino como una estructura nueva, como una organización verdaderamente integrada y que trabaja en red.

Al respecto se deduce que gobierno abierto es aquel que entabla una constante conversación con los ciudadanos con el fin de escuchar lo que ellos dicen y solicitan, que toma decisiones basadas en sus necesidades y teniendo en cuenta sus preferencias, que facilita la colaboración de los ciudadanos y funcionarios en el desarrollo de los servicios que presta, y que comunica todo lo que decide y hace de forma abierta y transparente. 
CUARTA: La transparencia es el elemento principal de un Gobierno Abierto. Se basa en considerar que todos los datos producidos por la administración pública, son datos públicos, es así que la transparencia consiste en proporcionar a la sociedad toda información que se produce sobre sus procesos de gestión, formulación e implementación de sus políticas públicas, sobre la ejecución de sus programas, como medio para conocer los niveles de desempeño gubernamental, vigilar la utilización de los recursos públicos y facilitar la rendición de cuentas.

Es así, que la transparencia es esencial para atender las necesidades de información social, mejorar la imagen y recuperar confianza en el gobierno, además puede mejorar el diseño e implementación de las políticas públicas, combatir la corrupción y promover la participación ciudadana. Sin embargo, la información gubernamental es transparente en la medida en que sea accesible, se proporcione en formatos abiertos, usables y reutilizables y bajo licencias abiertas, en lo cual juegan un papel relevante las Tecnologías de la Información y Comunicación.

QUINTA: La participación ciudadana ha sido desde sus orígenes un elemento indispensable para el desarrollo de las regiones, es un elemento incondicional del consenso de las actividades de gobierno, ya que sin este la legitimidad de las instituciones carece de fundamento.

Asimismo, la participación ciudadana sustenta al Gobierno Abierto, constituye la base de muchos de los otros temas vinculados a las políticas de gobierno abierto, la ciudadanía activa suele ser un enlace vital entre la transparencia y la rendición de cuentas.

De igual manera es importante que la participación ciudadana se diseñe correctamente, cuente con recursos adecuados y nazca del deseo genuino de involucrar al público y de tener en cuenta sus aportaciones.

Unos cauces bien diseñados de participación ciudadana pueden promover un funcionamiento democrático más eficiente, legitimar al gobierno, implementar con éxito nuevas medidas y lograr nuevos resultados sociales.
SEXTA: Para que realmente se tenga un gobierno abierto, requiere de la colaboración y ello se trata de ir más allá de la participación, se busca canalizar propuestas, esfuerzos e incluso recursos que los ciudadanos y las organizaciones de la sociedad civil estén dispuestos a aportar en el proceso de diseño, implementación y control de las políticas públicas. Un gobierno colaborativo compromete e implica a los ciudadanos y demás agentes sociales en el esfuerzo por trabajar conjuntamente para resolver los problemas públicos. Sin embargo, la colaboración requiere de un trabajo en grupo, donde la experiencia y el conocimiento se unen para crear, producir e innovar, en lo cual juega un papel relevante la producción, difusión y reutilización de información, que se ha facilitado y potenciado con el uso de las Tecnologías de la Información y Comunicación.

\section{Referencias}

BÁRCENA Ibarra, A. (2015), Discurso en Ceremonia de Inauguración de la III Conferencia Regional de Datos Abiertos para América Latina y el Caribe, Centro Cultural Gabriela Mistral, Santiago de Chile, 9 de septiembre de 2015. Disponible en: http://www.cepal.org/es/discursos/iii-conferenci a-regional-dedatos-abiertos-para-america-latina -y-el-caribe.

BEETHAM, D. y Boyle, K. (1996). Cuestiones sobre la democracia. Madrid, España: Los libros de la catarata.

CALDERÓN, César y Sebastián Lorenzo (coords.) (2010), Open Government. Gobierno Abierto, España: Algón Editores.

CAMPOS Domínguez y Ana Eva Corojan (2012), "Estado del arte del Gobierno Abierto: promesas y expectativas", en A. Hofmann, A. Ramírez Alujas y J. A. Bojórquez Pereznieto (coords.), La promesa del Gobierno Abierto, Itaip/InfoDF.

CONCHA, Gastón y Alejandra Naser (Editores) (2012), El desafío hacia el gobierno abierto en la hora de la igualdad, Santiago de Chile: CEPAL.

DAHL Robert, (2006), La democracia. Una guía para los ciudadanos, Taurus, Buenos Aires, Argentina.

MADRIGAL-GUERRERO, Susana. Necesidad de un gobierno abierto en México. Revista de Aplicaciones del Derecho. 2019 
DASSEN, Nicolás y Juan Cruz Vieyra (Editores) (2012), Gobierno Abierto y transparencia focalizada, tendencias y desafíos para América Latina y el Caribe, Estados Unidos de América: Banco Interamericano de Desarrollo.

FERNÁNDEZ SANTILLÁN, José F., (2013), LA DEMOCRACIA COMO FORMA DE GOBIERNO, Instituto Federal Electoral, OXFORD, México.

HERNÁNDEZ, Patricia (2012), "Tendencias y primeros resultados de países a la vanguardia", en Gastón Concha y Alejandra Naser (Editores), El desafío hacia el gobierno abierto en la hora de la igualdad, Chile: CEPAL/Naciones Unidas.

MARTÍNEZ Puón, Rafael (2012), "Gobierno Abierto: ¿Más gobierno o más ciudadanía?”, en A. Honfman, A. Ramírez Alujas, y J. A. Bojórquez Pereznieto (coords.), La promesa del Gobierno Abierto, Itaip/InfoDF.

MILL, J.S. (1994). Del gobierno representativo, Tecnos, Madrid, España

MORALES Gutiérrez, Alfonso. (2011). "Innovación "abierta" en el Tercer Sector: El modelo organizativo 2.0". Revista Española del Tercer Sector, $\mathrm{N}^{\mathrm{o}} 13$, septiembre-diciembre, Madrid (pp. 17 - 37).

OCDE (2010), OECD Guiding Principles for Open and Inclusive Policy Making. Background document for expert meeting on "Building an open and inovative government for better policies and service delivery", Paris, 8-9 june 2010.

OSZLAK, Oscar (2016), "Gobierno Abierto: el rumbo de los conceptos" en Issa Luna Pla y José Antonio Bojórquez Pereznieto (coords), Gobierno Abierto y el valor social de la información pública, México: Instituto de Investigaciones Jurídicas de la UNAM.

OSZLAK, Oscar y Ester Kaufman (2014), Teoría y práctica del gobierno abierto: lecciones de la experiencia internacional, IDRC/CRDI.

QUINTANILLA Mendoza, Gabriela y José Ramón Gil García (2013), Gobierno abierto en América Latina: modelo conceptual, planes de acción y resultados preliminares, México: INAP/GLAP/IICA.
RAMÍREZ Alujas, Álvaro (2011), "Gobierno Abierto y modernización de la gestión pública: tendencias actuales y el (inevitable) camino que viene. Reflexiones finales", Revista Enfoques, vol. IX, no. 15, pp. 99-125.

(2013). El gobierno abierto y los desafíos tecnológicos en latinoamérica. Tecnos, Madrid, España.

(2013). Gobierno abierto. Eunomía. Revista en Cultura de la Legalidad, 5,G 204.

ROUSSEAU, Jean-Jacques (1993), El contrato Social, Editorial Altaya, España.

TICAS Ríos, Elvira Magdalena (2011), Ética y Valores 1, $3^{a}$ ed., Ed. ST, México. 